\title{
¿UnA MICROHISTORIA TOTAL DE SiMOJOVEL?
}

\section{A Complete Micro-History of Simojovel?}

\author{
Óscar Javier Barrera-Aguilera*
}

DOI: https://doi.org/10.29043/liminar.vl8i2.770

Reseña de Espacios sociales en una región agraria del norte de Chiapas (siglos XIX-XXI), de Sonia Toledo Tello. San Cristóbal de Las Casas, Chiapas: CIMSUR-UNAM, 2019.

$\mathrm{E}$ libro Espacios sociales en una región agraria del norte de Chiapas (siglos $X \mathrm{I} X-X X \mathrm{X}$ ) es una versión revisada del trabajo presentado por la antropóloga Sonia Toledo Tello para obtener el grado de doctora en Estudios Mesoamericanos en la Universidad Nacional Autónoma de México. No es la primera vez que esta investigadora se ocupa de estudiar la historia social de Simojovel, un municipio ubicado al norte de Chiapas. Por tal motivo, la siguiente reseña tratará de sopesar el grado de originalidad y coherencia de este trabajo en vinculación con dos libros que la misma autora publicó con anterioridad.

La primera ocasión que la antropóloga visitó Simojovel para realizar trabajo de campo fue entre los años 1985 y 1989. El resultado de esa temporada de investigación fue la redacción del libro titulado Historia del movimiento indígena en Simojovel, 1970-1989, que trata sobre el movimiento campesino que tuvo lugar en la región a lo largo de las décadas del periodo indicado (Toledo, 1996). Con respecto a este primer trabajo, el segundo libro de Sonia Toledo (2002), titulado Fincas, poder y cultura, presentó varias novedades. La

\footnotetext{
* Óscar Javier Barrera-Aguilera. Doctor en Historia por El Colegio de México, México. Posgrado de Antropología Socialenla Escuela Nacional de Antropología e Historia (ENAH), México. Temas de especialización: historia de la ladinización en Chiapas y de la antropología en América
}

primera de ellas consistió en que el foco de atención fueron los propietarios de las haciendas, y la segunda en que la autora quiso subrayar — más allá de las evidentes diferencias - un conjunto de prácticas y representaciones compartidas tanto por los finqueros como por los trabajadores, lo que ella denominó la "cultura de finca" (Toledo, 2002).

Transcurridos quince años de haber sido publicado el segundo libro de Sonia Toledo, en el año 2019 apareció Espacios sociales en una región agraria del norte de Chiapas (siglos XIX-XXI). Varios aspectos hacen diferente este trabajo de los dos anteriores. En primer lugar, la antropóloga dedica sus esfuerzos a estudiar el proceso de formación de ejidos entre los años 1930 y 1960, lo que le permite afirmar que, a pesar de la Reforma Agraria, en la región de Simojovel se mantuvo el poderío de las fincas. Otro de los vacíos que llena esta investigación es el estudio de lo que la académica denomina la transformación de los trabajadores de las fincas en campesinos. Asimismo, una importante novedad que presenta es el tratamiento de una faceta de la cuestión agraria anteriormente no atendida: la construcción

Latina. Correo electrónico: cayatano68@yahoo.com. ORCID: https:// orcid.org/0000-0002-7704-9596

Recibida: 7 de mayo de 2019. 
ideológica particular resultado de los juegos políticos entre el gobierno federal, la Iglesia católica y las organizaciones no gubernamentales.

La manera de enfocar los temas investigados también es diferente en este tercer documento, donde la autora da prioridad tanto al impacto de las políticas agrarias a nivel local, como a la variedad de los problemas agrarios que se presentaron en Simojovel a lo largo de 150 años. Sin abandonar el reconocimiento de que las relaciones sociales son diversas, cambiantes y desiguales, en esta ocasión Sonia Toledo atiende a las diferentes formas en que los habitantes de la región se han relacionado con la tierra. Asimismo, ha reformulado los conceptos: por una parte, entiende los espacios sociales como productos concretos e históricos de las personas que los ocupan y, por otra, analiza los movimientos campesinos conforme a criterios de seguridad, materialidad, autonomía y movilidad. Analiza, además, que el Estado en sí mismo no es entendido como una institución, sino como el resultado de grupos humanos en condiciones locales, y revisa las comunidades, por su lado, en términos de sus tensiones y transformaciones; por último, los campesinos son asumidos como grupos heterogéneos y desiguales en su interior.

Una notable fortaleza de este tercer proyecto académico es la variedad de fuentes empleadas para dar cuenta de los diferentes periodos históricos. El Archivo Histórico Diocesano de San Cristóbal de Las Casas, Chiapas, es la base para reconstruir la historia de Simojovel y Huitiupán a lo largo del siglo XIX, mientras que para las transformaciones agrarias que tuvieron lugar tras la Revolución, la autora acude a los expedientes agrarios que reposan en el Registro Agrario Nacional en la Ciudad de México. Emplea también la autora los censos y las memorias de gobierno para ofrecer una imagen dinámica de la población en la región. Y, desde luego, los testimonios recogidos en campo complementan la información documental y ofrecen un acercamiento a los acontecimientos más recientes.

Elenfoque, los conceptosy las fuentes anteriormente descritos permiten que Sonia Toledo alcance resultados realmente novedosos. El capítulo uno, por ejemplo, recalca que la formación de las fincas no fue resultado de las leyes liberales de mediados del siglo XIX, ni tampoco de las políticas agroexportadoras del porfiriato, sino de la conjunción de la decadencia de los pueblos de indios tras la llegada de ladinos pobres dedicados a la arriería. Con lo anterior, la autora cuestiona el mito del arribo de finqueros ricos a la región y también la idea de la introducción de la producción moderna para un mercado internacional. De igual modo, el auge de Simojovel y la decadencia de Huitiupán durante ese mismo periodo son acontecimientos de suma importancia para comprender lo que sucedió posteriormente. Sobre este punto la investigación también cuestiona la "leyenda negra" que se ha tejido con relación a las fincas, pues, sin desconocer la explotación que significó el trabajo servil, estas también fueron vistas por los trabajadores como una alternativa laboral ante la crisis en que se encontraban los pueblos de la región.

En conexión con lo anterior, Sonia Toledo muestra en el capítulo dos que los trabajadores permanecieron en las fincas no tanto por la manipulación y el engaño que pudieron haber ejercido sobre ellos los grupos poderosos, sino por su propia elección, atendiendo a la seguridad y protección que podían encontrar en esos espacios. En este sentido, y considerando que los finqueros mantuvieron el control sobre las mejores tierras, puede entenderse que, si bien el reparto agrario introdujo modificaciones, no consiguió anular el predominio de las fincas. Algunos de los ejidos que se constituyeron entre las décadas de 1930 y 1960 conservaron muchas de las prácticas religiosas, comerciales y crediticias que los ataron a la esfera de influencia del grupo finquero. Una de las paradojas que se presenta en este apartado es que el reparto agrario se produjo a partir de 1970 no por iniciativas gubernamentales, sino por acción de organizaciones agraristas locales, lo cual en parte explica el carácter violento que revistió el proceso.

La distancia entre los objetivos del movimiento agrario y lo que sucedió en la práctica es la materia que compone el capítulo tercero. En él, a través de tres estudios de caso la autora revela la diversidad 
de orígenes de las poblaciones que se crearon a partir de 1980. Las historias de vida que recopiló en campo permiten observar la diferencia entre el ejido comunitario idílico y las tensiones que se produjeron entre los propios campesinos, porque algunos defendían la toma de tierras mientras otros se oponían a la misma.

El capítulo cuatro se centra en lo que podría denominarse el posconflicto: el cambio de la vida en las fincas a la vida en comunidades. La nota común consistió en que concretamente estas nuevas formas de organización no fueron homogéneas ni tampoco igualitarias, además de que las diferencias de género, edad y riqueza estuvieron a la orden del día. Es más, algunas de las nuevas poblaciones ni pertenecieron a la organización campesina ni tuvieron un proyecto igualitario porque, por ejemplo, en lugar de la propiedad comunitaria en muchas ocasiones se privilegió la compraventa de tierras. Otro tanto puede decirse con respecto a las variadas experiencias de los finqueros tras el reparto agrario de la década de 1970, porque sus trayectorias de vida dependieron de las diferencias económicas y de las habilidades para la negociación, entre otros factores.

El último capítulo de la investigación se ocupa de las formas de vida en las comunidades campesinas a lo largo de la última década del siglo XX y la primera del XXI. En esta sección el énfasis se dirige a estudiar el impacto específico que la política agraria y el Ejército Zapatista de Liberación Nacional (EZLN) tuvieron en la región de Simojovel. Una primera paradoja que permite vislumbrar este enfoque, que atiende a las adaptaciones locales que sufrieron procesos más amplios, es que, mientras en la región se llevaba a cabo una lucha por la tierra, a nivel nacional se presentaba una crisis general del sector agrícola. A su vez, el estudio del origen y la expansión del neozapatismo en la zona muestra que la participación en dicho movimiento no respondió a la necesidad de recuperar las tierras - lo cual ya se había conseguido con anterioridad-, sino a las condiciones de exclusión, violencia y maltrato que día a día continuaban padeciendo los campesinos.
El estudio de las experiencias específicas de las comunidades que sirvieron de apoyo al EZLN también saca a la luz las dificultades que se presentaron para cumplir los compromisos adquiridos con esta organización, así como también las divisiones políticas al interior de las poblaciones. Resulta revelador que la presencia de este movimiento no fue dominante en la región, sino que convivió con otras organizaciones que exigieron el reconocimiento de lo que sus propias luchas habían conseguido con anterioridad. A su vez, la complejidad del asunto se incrementa al observar las razones por las cuales muchas poblaciones -inicialmente rebeldes - terminaron por aceptar las ayudas ofrecidas por el gobierno federal, como por ejemplo la regularización de las propiedades agrarias, un asunto pendiente tras el violento movimiento campesino.

En conclusión, esta investigación consigue dar cuenta de la manera sorprendente como los agentes sociales han contribuido a transformar la región de Simojovel, en un principio, desde los pueblos de indios a las fincas y, más recientemente, desde estas a las comunidades campesinas.

En pocas palabras, la lectura de este nuevo libro resulta enriquecedora en varios sentidos. Paradójicamente, hoy en día no es común estudiar regiones concretas ni mucho menos su transformación a lo largo de un periodo de tiempo extenso. De manera adicional, tampoco es usual que una misma autora no solo rebata sus anteriores apreciaciones, sino que vuelva sobre ellas y consiga dar seguimiento a un tema desde su inicio hasta su cierre. Sonia Toledo logra reconstruir el origen, desarrollo y declive de las fincas de Simojovel, a través de diferentes fuentes documentales, desde una perspectiva original y con gran destreza en la escritura.

\section{Referencias}

Toledo Tello, Sonia (1996). Historia del movimiento indígena en Simojovel, 1970-1989. Tuxtla Gutiérrez, Chiapas: IEIUNACH, Serie Monografías 6.

Toledo Tello, Sonia (2002). Fincas, poder y cultura en Simojovel, Chiapas. México: PROIMMSE-UNAM/IEI-UNACH. 